\title{
Application of CLT in Computer-Based Teaching of Listening and Speaking
}

\author{
Yuhui Liu \\ College of Foreign Languages, Beijing University of Technology, Beijing, China \\ Email: liuyuhui5786@163.com \\ Received 2 March 2014; revised 9 April 2014; accepted 18 April 2014 \\ Copyright (C) 2014 by author and Scientific Research Publishing Inc. \\ This work is licensed under the Creative Commons Attribution International License (CC BY). \\ http://creativecommons.org/licenses/by/4.0/

(c) (i) Open Access

\begin{abstract}
This paper introduces the theory of communicative competence by Hymes, the interpretation of communicative competence by Canale \& Swain, the elements of efficient communication by Widdowson respectively, and the limitation of the previous application in China with the teaching environment of Classroom plus blackboard, analyzes the necessity and feasibility of creating authentic communicative environment by using communicative language teaching (CLT) in teaching listening and speaking with the help of computers and websites, and discusses the components of the learning and teaching model in the authentic communicative environment by using CLT with the feedback and evaluation from both the students and the teachers.
\end{abstract}

\section{Keywords}

Communicative Language Teaching (CLT), Authentic Communicative Environment, Teaching of Listening and Speaking

\section{Introduction}

Communicative language teaching (CLT) has ever held its way in the college English teaching in China. The Functional and Notional Category in the College English Teaching Syllabus (revision) issued in 1999, was based on "the theory of communicative competence", aiming at developing students' abilities to use English to communicate. However, for the limitations of the class teaching environment, it is difficult to create an authentic communicative environment, and the in-class teaching activities are merely those related to the teaching content in class, such as pair-work, group discussion, role-play, and so on. All these activities are performed in artificial environment; as a result, without teaching materials and classrooms, students are still not able to communicate. There are limitations to the use of CLT due to factors such as neglect of errors, emphasis on global meaning, and what is more, big class size and unreal peer communication (Dan Lu \& Julie Y. F. Ng, 2013: pp. 289-294). 
However, with the teaching reform of college English, the publication of College English Curriculum Requirements, and the introduction of computers and network to English teaching and learning, it is time to discuss the theories of CLT, and the necessity and feasibility of its application in English teaching and learning, especially in teaching listening and speaking.

\section{The Theory of CLT and Its Application in China}

\subsection{Hymes' Communicative Competence}

In 1972, Dell Hymes put forward the concept-communicative competence. In his opinion, language is a kind of phenomenon, which is related to society and culture, and the research should be carried out in the real social environment instead of focusing on sentence structures. In Hymes' words, there are "rules of use without which the rules of grammar would be useless." Hymes' communicative competence includes four aspects: 1) whether something is formally possible; 2 ) whether something is feasible in virtue of the means of implementation available; 3 ) whether something is appropriate in relation to a context in which it is used and evaluated; 4) whether something is in fact done, actually performed, and what its doing entails (Hymes, 1972: pp. 269-293).

According to Hymes' communicative competence, the aim of teaching a foreign language is not only to impart the students the language code or forms of the language, but also to develop their communicative competence in real environment. Foreign language teaching should be combined with the target culture and the real environment where the language is used. So in foreign language teaching, the communicative function of the teaching process and the authenticity of the teaching content should be paid more attention to.

\subsection{Canale and Swain's Interpretation of "Communicative Competence"}

In 1980, from the language teaching point of view, Canale and Swain interpreted "communicative competence" further and classified it into four aspects: 1) Grammatical competence. It mainly refers to the knowledge and skill related to the way the language works as a system, including vocabulary, grammar, pronunciation, morphology and so on. 2) Social competence. It includes the culture, convention and etiquette of the target language and the competence of understanding and using the target language in any given social linguistic environment. 3) Discourse competence. It mainly refers to the competence of combining the form of language with the meaning of language according to different types of literature (e.g. narration, scientific report, business letter, literature and so on), forming a coherent conversation or discourse. Through linking up grammatical forms and different meanings coherently, the discourse is thus formed. 4) Strategic competence. It refers to the various skills and methods the addresser adopts, aimed at completing the conversation or improving the communicative effect (Canale \& Swain, 1980: pp. 1-47).

\subsection{Widdowson's Four Elements of Efficient Communication}

In 1978, Widdowson put forward the four elements of efficient communication, which are the same with Canale \& Swain's on the whole. The four elements include: 1) certain linguistic knowledge; 2) the ability to use the linguistic knowledge; 3 ) the communicative competence; 4) some knowledge about society and culture (Widdowson, 1978: pp. 2-4, 67-69).

Hymes' communicative competence, Canale \& Swain's interpretation of "communicative competence" and Widdowson's four communicative elements have paved the way for the shaping of Communicative Language Teaching.

\section{The Necessity and Feasibility of Creating the Authentic Communicative Environment}

\subsection{Necessity}

With a view to keeping up with the new developments of higher education in China, deepening teaching reform, improving teaching quality, and meeting the needs of the country and society for qualified personnel in the new era, College English Curriculum Requirements (Requirements hereafter) is drawn up by Ministry of Education (2007), with the objective that "College English is to develop students' ability to use English in an all-round way, especially in listening and speaking, so that in their future work and social interactions they will be able to ex- 
change information effectively through both spoken and written channels, and at the same time they will be able to enhance their ability to study independently and improve their cultural quality so as to meet the needs of China's social development and international exchanges." It is thus clear that, the ability of listening and speaking occupies a very important position in college English teaching.

Because of the differences of different regions, colleges and students, the requirements for undergraduate College English teaching are set at three levels, i.e., basic, intermediate and higher requirements. The ability of listening in the three levels includes: "being able to follow everyday conversations and lectures on general topics conducted in English; being able to understand Special English programs spoken at a slow speed", "being able to follow, in the main, talks and lectures by people from English-speaking countries, and to understand longer English radio and TV programs produced in China on familiar topics", and "being able to understand radio and TV programs produced in English-speaking countries". And the ability of speaking of the three levels includes: "students should be able to talk about topics with people from English-speaking countries"; "students should be able to hold conversations in fairly fluent English with people from English-speaking countries"; "students should be able to deliver papers at academic conferences and participate in discussions". The above requirements for students' ability are set at three levels, from basic to higher, and all the requirements are aimed at the application of language in everyday life and work. So it is necessary to create the authentic communicative environment in foreign language teaching.

\subsection{Feasibility}

In order to achieve the objective of College English teaching, the Requirements put forward a computer- and classroom-based multi-media teaching model. "The model places a premium on individualized teaching and autonomous learning, and makes full use of the special function of computers in assisting learners with individualized and repeated language practice, especially with the training of listening and speaking abilities. Teachers can give students guidance in learning in class and can impart the skills and knowledge of reading, writing and translation to them. With teachers' help and in respect to their own characteristics, levels and time, students can be assisted by computers in choosing the appropriate content, so that their all-round ability to use English can be improved and the best effects of learning achieved."

Introducing the computers and websites into the college English teaching can facilitate the creation of authentic communicative environment. "the websites create an open, multicultural, authentic and multimedia foreign language learning environment" (Guan \& Zheng, 2004: pp. 143-146). Compared with the traditional written teaching material and classroom teaching, the website teaching material and computers provide students with fictitious communicative environments which are closer to the authentic ones. In the process of learning online, students may understand and get to know the communicative activities in different scenes through watching, listening and imitating by using computers; through demonstrations of teacher-student and student-student communicative activities in class, examinations and other means, students may grasp and consolidate all kinds of communicative skills and ability.

Moreover, the appropriate teaching material is also conducive to the creation of authentic communicative environment. For instance, the teaching material New Horizon: Viewing, listening and Speaking is designed from the easy to the difficult in its themes, and it starts with the students' daily life and then gradually moves to topics which are a little more abstract and profound in meaning ( $\mathrm{Xu}, 2004)$. Students may express their thoughts and ideas related to the topics. The teaching material is a combination of books, cassettes, disks, and network. "The different carriers have different advantages; they complement each other and support each other, providing conditions for individualized and autonomous teaching and learning. This teaching material takes full advantage of the technology of sound-image, adopting rich resources, vivid forms, training with clear aims and efficient administration, to improve the students' practical communicative ability" (Requirements). The teaching environment that is created by the teaching material is also the authentic communicative environment with which the students identify, and thus their enthusiasm and interest can be evoked.

\section{Components of the Learning and Teaching Model in the Authentic Communicative Environment}

\subsection{Autonomous Learning}

The development of students' autonomous learning, based on the Constructivism, has been paid more and more 
attention to. "According to the Constructivism, teachers are supporters of students' construction of their knowledge, and students are constructors of their knowledge. In the teaching process, instead of acquiring knowledge passively, students construct their knowledge actively. Learners should not wait for the imparting of knowledge, but based on their special experience obtained, construct their own knowledge with their own experience and significance. Since the enthusiasm, constructivism, accumulation, aim-direction, diagnosis and reflection, exploration, environment, sociality of learning, and inner-driven learning are stressed in constructivism, learning, instead of teaching, should be the focus in the teaching process. Aiming at getting the students to participate in learning process through fulfilling the authentic life task, the initiative and enthusiasm of students should be fully brought into play, and the task-based teaching should be advocated, and as a result, the teaching focus may be transferred from "outcome" to "process" (H.K. Xiong \& D.L. Xiong, 2004: pp. 141-143).

The concrete process of autonomous learning is: based on the teaching content and teaching schedule, teachers may assign tasks to students, and students may learn autonomously online. The learning process is mainly through the person-computer communication (listening, watching, and imitation) and a great quantity of input, and students may complete the required content and elective content, and other related content which students are interested in. In view of the different types of task, the autonomous learning includes individual learning and cooperative learning in pair or group forms.

To ensure the efficiency of autonomous learning, teachers should first develop students' competence of using the learning strategies, which include "the cognitive strategies enabling learners to deal with and develop the input language knowledge, and the metacognitive strategies used for monitoring, adjusting or self-management" (O'Malley \& Chamot, 1990: p. 142). The effective learning strategies may help students form the following abilities: 1) to be able to have a clear aim of learning, and according to the general aim, make short-term and longterm aims and plans for each semester and phase, and pay attention to the accumulation of the learning process, as a result, the teaching requirements can be achieved; 2) to be able to select the input to ensure it is understandable, effective, and related to the phase aim and general aim; 3 ) to be able to self-monitor and self-evaluate, which means evaluating and reflecting upon their method of learning and learning effect, finding out the problems initiatively, taking measures in time, adjusting learning process continuously, and establishing new learning aim further; 4) with the development of learning, students may enhance their thirst for knowledge and keep the interest in and enthusiasm for learning, thus completing the shift from "being required to learn" to "requiring to learn"; 5) to be able to learn consciously, and change the "external and instrumental motives" into "internal and integrative ones" (Crookes \& Schmidt, 1991; as cited in Xiao, 2002: pp. 24-27); 6) to be able to develop the ability of cooperative learning, and the large quantity of input in autonomous learning may be digested, assimilated, and consolidated through one-to-one communication or group member discussion. Moreover, "in these activities, on the one hand, collective thinking and wisdom can be shared by everybody; on the other hand, the collision and communication of different ideas may facilitate the development of students' dialectical thinking and divergent thinking" (Xiao, 2002: pp. 24-27). Directing autonomous learning with effective strategies, adjusting learning strategies continuously in learning process, and forming suitable and peculiar methods of learning are not only the guarantee of successful learning but also the basis of the development of autonomous learning and persistence in learning for life.

\subsection{Classroom Communicative Activities}

The classroom teaching emphasizing the authenticity of environment should no longer be the teacher-centered cramming method of teaching, but the task-based activities created by the Communicative Language Teaching method, the problem-solving activities, namely student-centered activities. The specific procedures are: 1) Teachers assign tasks. These tasks include different kinds of tasks, such as self-completed tasks, tasks requiring cooperation with others, and group-completed tasks, which are required to be finished in the autonomous learning outside class. 2) Classroom activities. The students, with different tasks, report or demonstrate their assignments in individual, pair or group forms. These activities are the output activities, which are completely based on the learning of input, especially the activities in pairs or groups, and can be viewed as the person-person communication in the authentic environment. 3) After each activity, teachers may evaluate it by identifying the achievements, pointing out the deficiency and the aspects needing to be paid attention to and improved in the next phase of learning. The evaluation should consist of scores and comments. To get students pay more attention to the learning process, every activity should be given a score which can be included in the summative as- 
sessment; the comment can be a part of the formative assessment, and provide students with guidance for improvement.

Instead of the autonomous learning, where students may get help and instructions from teachers, mainly focusing on large quantity of input, classroom teaching should mainly focus on the effective output. In this teaching model, students are the center, while teachers must play an appropriate role. Constructivism holds that teachers should play the following roles in the teaching process: 1) Designers and organizers. Teachers, just as in the traditional teaching environment, are still the designers and organizers in classroom, but in the environment of computers and network technology, teachers should focus on developing and cultivating students' ability of autonomous learning and creating the atmosphere facilitating language output. In the new teaching environment, teachers may make full use of computers and network, bringing students into speaking activities through the effective design of classroom activities. 2) Assessors and diagnosers. "Education is a very complex process, relating closely to linguistics, sociology, psychology, and so on. Teachers need to know and study individual differences among language learners, and discover sensibly the difficulties and problems in their different leaning phases, and then design new teaching methods to solve these problems" (Qu, 2004: pp. 78-80). 3) Facilitators. On the basis of analyzing the problems students encounter in different learning phases, teachers need to provide platform for their autonomous learning; as a result, they may acquire the skills of learning language and the optimal learning effect. By playing the role of facilitators, teachers may help students find out the optimal learning strategies appropriate for themselves, urge students to form the behavior consciousness, confidence and capability of self-learning. 4) Controllers. Teachers are controllers not only in the classroom teaching but also in the autonomous learning. In the teaching environment of computers and network technology, on the one hand, students are faced with the information wave and varied information media all over the world; on the other hand, there are great differences among the students' ability to use information instrument to acquire and analyze information. As a result, students sometimes can't help deviating from the subject of teaching and do some other unrelated things. So it is necessary for teachers to supervise and manage students in time, and in the meantime correct their deviation and bring them back to the correct teaching path through assigning tasks and check in class.

\subsection{After-Class Communicative Activities}

From the plans of autonomous learning and classroom teaching discussed above, it can be concluded that for the time of learning in class is limited, there are more opportunities of input than those of output. So some traditional after-class activities, especially the oral activities, such as lectures, debates, English corners, and participation in social activities with foreign teachers or students, as the supplement for classroom activities, should not be neglected. Actually, these activities are authentic communicative activities in the authentic environment. Besides, by participating in multi-lingual organizations, students may use English to communicate both in school and outside school, and by using English to communicate successfully, they may obtain happiness and strengthen themselves, and be a foreign language learner for life (H.K. Xiong \& D.L. Xiong, 2004: pp. 141-143).

\section{Teaching and Learning Feedback}

The teaching model discussed above has been adopted for a year in our university. The following is the evaluation of our teachers and feedback of the students.

1) The feedback of questionnaire

The students have gradually adapted to the new teaching model, the result is: the rate of satisfaction in the first semester is $60 \%$, and in the second semester, it is up to $85 \%$.

2) Teachers' evaluation

The following is the evaluation given by our teachers in a discussion at the end of the year.

a) When tested in class, some students felt nervous and could not open their mouths (zero point appeared in the first and second time). Now they can face the oral test with ease and confidence (the passing rate in the final oral examination is $93.6 \%$ ).

b) Some students have had obvious improvement in pronunciation and intonation owing to imitating the native speakers online.

c) Some students could weave the vocabulary, structure, sentences of the teaching material initiatively into their dialogues, and could accumulate oral material consciously. 


\section{3) Students' feeling}

The following are the students' feeling about the new model at the end of the year.

a) We like the new teaching model.

b) The content of the audio-visual-oral material and $\mathrm{CD}$ are vivid, interesting and attractive.

c) We believe that this model can facilitate the enhancement of our ability in listening and speaking.

\section{Conclusion}

In conclusion, the new teaching model carried out in the computer- and web-based teaching environment, in which CLT is adopted, is a teaching model worthy of exploration because it can create the authentic or nearly authentic language communicative environment for students, and it can use the teaching method of studentcentered autonomous learning, in- and after-class communicative activities directed by teachers to develop students' communicative competence.

\section{References}

Canale, M., \& Swain, M. (1980). Theoretical Bases of Communicative Approaches to Second Language Teaching and Testing. Applied Linguistics, 1, 1-47. http://dx.doi.org/10.1093/applin/I.1.1

Guan, B., \& Zheng, S. T. (2004). Interaction in the Web-Assisted Foreign Language Teaching. Journal of Sichuan International Studies University, 2, 143-46

Hymes, D. (1972). On Communicative Competence. In J. B. Pride, \& A. Holmes (Eds.), Sociolinguistics: Selected Readings. Harmondsworth: Penguin.

Lu, D., \& Ng, J. Y. F. (2013). The Pedagogical Maze: Retrospection on CLT in Hang Kong. Open Journal of Modern Linguistics, 2, 289-294. http://dx.doi.org/10.4236/ojml.2013.34036

Ministry of Education (2007). College English Curriculum Requirements. Beijing: Foreign Language Teaching and Research Press.

O’Malley, J., \& Chamot, A. (1990). Learning Strategies in Second Language Acquisition. Cambridge: Cambridge University Press.

Qu, W. J. (2004). The Student-Oriented Teaching Method and Role Switch of English Teachers. Journal of Xi'an International Studies University, 2, 78-80

Widdowson, H. G. (1978). Teaching Language as Communication. Oxford: Oxford University Press.

Xiao, F. (2002). How to Foster Learner Authority. Foreign Language World, 6, 24-27.

Xiong, H. K., \& Xiong, D. L. (2004). Syllabus, Norm and English Teaching Reform in China. Journal of Sichuan International Studies University, 1, 141-43.

Xu, Z. (2004). New Horizon College English: Viewing, Listening and Speaking. Beijing: Foreign Language Teaching and Research Press. 